\section{Checking lists, ticking boxes}

Although not original, the story makes an interesting introduction to the topic: Boeing's prototype B-17 bomber stalled and crashed in 1935 on its first flight because the elevator control was left locked. ${ }^{1,2}$ The combination of the loss of life and the potential loss to the firm of the US government procurement demanded an innovative approach - and thus the checklist was born. The B-17 programme went on to build over 13,000 aircrafts. It took over 70 years for the checklist to enter mainstream medicine, with Pronovost's checklist for the prevention of central line infections, which reduced line infection rates from $11 \%$ to zero in Johns Hopkins. ${ }^{3}$ The World Health Organization (WHO)'s surgical checklist was pioneered 7 years ago and is widely used; the UK National Patient Safety Agency (NPSA) recommended its adoption by the NHS in $2009 .{ }^{4}$ Hard evidence of reductions in complications and in-hospital mortality from the use of checklists has been reported from the Netherlands. ${ }^{5}$

In this issue of Clinical Medicine, Braham et al describe the evolution of checklist usage and its adaptation to different circumstances, instancing the NPSA's adaptations of the WHO surgical checklists to obstetric surgery and interventional radiology. ${ }^{6}$ With the NPSA's absorption into the National Health Service (NHS) Commissioning Board Special Health Authority in 2012 (subsequently the NHS Commissioning Board, subsequently NHS England), issuance of checklists by the NHS halted. The year 2014 has, however, been identified as a year for special attention to patient safety by NHS England's safety director, with the launch of a nationwide programme to design patient safety initiatives. ${ }^{7}$ February saw the publication of the report of the NHS Never-Events Task Force Standardise, educate, harmonise: Commissioning the conditions for safer surgery. ${ }^{8}$

Surgery, with its central event of the operation, has perhaps appropriately been the focus for much of the drive towards a more disciplined, less variable and thus less error-prone approach. However, the factors identified by the task force as sources of surgical error - 'human fallibility, miscommunication, poor coordination of team activity, human-technology interaction and suboptimal management of the environment' - read equally well as sources of error in hospital medicine. The combination of unsafe systems and unsafe behaviours highlighted as lying behind surgical never-events lie equally behind medical accidents and mismanagement, including absent or inadequate training, particularly in team working and human factors, as well as inadequate staffing. The Task Force pointed to reducing variation by standardisation in the NHS as the first step to preventing never-events - and indeed improving safety in general - and praises and values the surgical checklists as a means to achieve this. It points out, however, that they are not a panacea, and improperly used can degenerate to a despised tick-box exercise.

In their paper, Braham et al report on the introduction of a local checklist in a medical setting, in the context of a cardiac catheter laboratory performing a wide variety of procedures. ${ }^{6}$ Their initial audit of the effect of using an unmodified WHO Surgical Checklist confirmed that specific modifications to fit the requirements of a cardiac catheter laboratory were essential to obtain buy-in from the staff; indeed the unmodified checklist was rarely completed and on occasions was manifestly incorrectly filled in. A modified checklist designed to be strictly relevant to the environment in which it was being used was substantially more acceptable, and its use may indeed have prevented critical incidents (though the study was not designed or powered to prove that).

It is difficult to imagine that current patient safety initiatives in the NHS will not move increasingly towards mandating the use of checklists, as part of a nationwide move towards standardisation and harmonisation. An appropriately formulated and completed checklist has been shown to safeguard patients; in a medico-legal context one would envisage the same checklist would also safeguard healthcare practitioners. The requirement will be to design such documents so that they are fit for purpose and, if so, they will be welcomed. But much needs to be done to achieve protocols appropriate for the huge number of procedures and scenarios that hospital medicine presents. To state the obvious, it is an area where only clinicians can lead.

$\begin{array}{ll}\text { Members of the editorial board } \\ \text { Professor Humphrey Hodgson } & \text { Dr Cordelia Coltart } \\ \text { Editor } & \text { International editor } \\ \text { Dr Paul Grant } & \text { Cono Ariti } \\ \text { Editorial registrar } & \text { Statistical editor }\end{array}$

Members of the editorial board

Dr Na'eem Ahmed

Paul Belcher

Dr Rodger Charlton

Dr Tahseen Chowdhury

Dr Kate Evans

Professor Brian Hurwitz
Dr Angela King Professor Martin McKee Dr Roby Rakhit

Dr Ian Starke

Dr Kevin Stewart 


\section{References}

1 World Health Organization. Patient Safety: The checklist effect. www.who.int/patientsafety/implementation/checklists/background/en [Accessed 4 August 2014].

2 Angle of Attack. What the B17 taught us about checklists. www. flyaoamedia.com/aoa/what-the-b17-taught-us-about-checklists/ [Accessed 4 August 2014].

3 Pronovost P, Needham D, Berenholtz S et al. An intervention to decrease catheter-related bloodstream infections in the ICU. $N$ Engl J Med 2006;355:2725-32.

4 NHS National Patient Safety Agency. WHO Surgical Safety Checklist, 2009. www.nrls.npsa.nhs.uk/resources/?EntryId45=59860 [Accessed 4 August 2014].

5 de Vries EN, Prins H, Crolla R et al. Effect of a comprehensive surgical safety system on patient outcomes. N Engl J Med 2010;363:1928-37.
6 Braham DL, Richardson AL, Malik IS. Application of the WHO surgical safety checklist outside the operating theatre: medicine can learn from surgery. Clin Med 2014;14:468-474.

7 NHS England. The biggest patient safety initiative in the history of the NHS - Mike Durkin, 2014. www.england.nhs.uk/2014/01/21/ mike-durkin-3 [Accessed 4 August 2014].

8 Patient Safety Domain. Standardise, educate, harmonise: Commissioning the conditions for safer surgery. Report of the NHS England Never Events Taskforce February 2014 . London: NHS England, 2014. www.england.nhs.uk/wp-content/uploads/2014/02/ sur-nev-ev-tf-rep.pdf [Accessed 4 August 2014].

Humphrey Hodgson

\title{
In praise of clinical examinations
}

\author{
Author: Andrew T Elder ${ }^{\mathrm{A}}$
}

It was a hectic morning rush hour on the interstate. Fresh off a trans-Atlantic flight, driving bumper to bumper on the 'wrong' side of the road at 60 miles per hour was never going to be straightforward, but the impeccable driving of my fellow road users made it all so easy. I was glad they had driving tests in America.

On a 3-month sabbatical to learn the American approach to the teaching and assessment of the bedside clinical skills of internal medicine residents, I arrived intrigued. Since 1972, US certification in internal medicine had been dependent on completion of a residency programme and safe passage through the American Board of Internal Medicine's knowledge-based examination. ${ }^{1}$ The system that I knew in the UK shared these characteristics but had one critical difference. Internal medicine trainees were also required to pass the summative bedside clinical skills examination PACES (Practical Assessment of Clinical Examination Skills). ${ }^{2}$ How would my American colleagues assess residents' bedside skills in the absence of such an examination?

The answer, I assumed, must lie with workplace-based assessments. Developed largely in America these assessments, such as the mini-CEX, ${ }^{3}$ were now also a mandatory part of internal medicine training in the UK. ${ }^{4}$ Our trainees liked the opportunities that they provided for direct observation of their skills and the subsequent feedback that they received from their trainers, but standardising the content, finding the time to

Author: ${ }^{A}$ honorary senior lecturer in medicine, Department of Medicine, Queen Mother Research Institute, College of Medicine and Veterinary Medicine, Edinburgh, UK deliver them in the busy environment of the National Health Service and translating a fundamentally formative exercise into a defensible summative process had all proved challenging. PACES had survived their introduction.

But to my surprise, the status and practice of workplace assessments were no different from the UK. Some members of the faculty, similar to colleagues in the UK, struggled to find the time to undertake them. Others, perhaps because they had grown up in the same system, felt that their own bedside clinical skills, particularly with regard to physical examination, were not sufficient to allow them to assess residency level trainees competently. Direct observation of trainees at the bedside was sporadic, unstructured and inconsistent. Competence in clinical skills was assessed in a loose, informal manner, and based largely on the ward-round impressions of attending physicians. A vague form of outcomes-based assessment seemed to operate in the minds of some, ie if the patients for whom the resident cared did 'OK', then the resident's clinical skills must also be 'OK'.

Puzzled, I reviewed the Accreditation Council for Graduate Medical Education (ACGME) curriculum for internal medicine. ${ }^{5}$ Physical examination and history taking were mentioned briefly, but seemed lost amidst a list of more abstract competencies, and the necessary levels of attainment and requirements for their assessment were unclear. Although the role of bedside skills, particularly physical examination, is increasingly questioned in technologically driven western healthcare environments, I doubted that these skills were being deliberately de-emphasised in a national medical curriculum, in this country, at this time. ${ }^{6}$ But, whatever the explanation, their low curricular profile made the lack of rigorous assessment less surprising.

I explained our traditional British ways at grand rounds and informal meetings. Knowledge assessments alone are not enough; 